\title{
Effect of dental implant surface roughness in patients with a history of periodontal disease: a systematic review and meta- analysis
}

\author{
Anton Dank ${ }^{1 *}$, Irene H. A. Aartman², Daniël Wismeijer ${ }^{1}$ and Ali Tahmaseb ${ }^{1}$
}

\begin{abstract}
Background: To review the literature on the effect of dental implant surface roughness in patients with a history of periodontal disease. The present review addresses the following focus question: Is there a difference for implant survival, mean marginal bone loss, and the incidence of bleeding on probing in periodontally compromised patients receiving a machined dental implant or rough surface dental implant?

Methods: Electronic and manual literature searches were conducted on PubMed/MEDLINE and the Cochrane Library on studies published until May 2018 to collect information about the effect of machined, moderately rough, and rough dental implant surfaces in patients with a history of periodontal disease. The outcome variables implant survival, mean marginal bone level, and the incidence of peri-implantitis and bleeding on probing were evaluated. Meta-analysis was performed to obtain an accurate estimation of the overall, cumulative results.

Results: Out of 2411 articles, six studies were included in this systematic review. The meta-analysis of the implant survival and implant mean marginal bone loss revealed a risk ratio of 2.92 (Cl 95\% 0.45, 18.86) for implant failure and a total mean difference of -0.09 (Cl 95\% - 0.31, 0.14) for implant mean marginal bone loss measured in a total group of 215 implants, both not statistically significant.

Conclusions: Due to lack of long-term data (> 5 years), the heterogeneity and variability in study designs and lack of reporting on confounding factors, definitive conclusions on differences in implant survival, and mean marginal bone loss between machined and moderate rough implants in periodontally compromised patients cannot be drawn. Future well-designed long-term randomized controlled trials are necessary to reveal that machined surfaces are superior to moderately rough and rough surfaces in patients with a history of periodontal disease.
\end{abstract}

Keywords: Dental implants, Implant surface, Periodontal, Bone loss

\section{Background}

Rough titanium implants are currently the standard treatment in implant dentistry [1]. They are roughly divided into three different types of surface roughness $\left(S_{\mathrm{a}}\right)$ : machined/minimal $( \pm 0.5 \mu \mathrm{m})$, moderate $(1.0-2.0 \mu \mathrm{m})$, and rough $(>2.0 \mu \mathrm{m})$ [2]. Generally, rougher implant surfaces have greater bone-to-implant contact [3]. In a

\footnotetext{
* Correspondence: a.p.dank@acta.nl

${ }^{1}$ Section of Oral Implantology and Prosthetic Dentistry, Academic Centre for Dentistry Amsterdam (ACTA), University of Amsterdam and Vrije Universiteit Amsterdam, Gustav Mahlerlaan 3004, 1081 LA Amsterdam, The Netherlands Full list of author information is available at the end of the article
}

randomized controlled clinical trial, it has been demonstrated that higher initial clinical survival rates are achieved when implants with a moderate rough surface are used, compared with machined implants [4]. Moreover, greater forces are required for rougher surfaced implants to be removed [5].

On the other hand, a disadvantage of this increased roughness might be that it facilitates bacterial adhesion at the implant surface [6]. Once they become exposed, rough surface implants are more vulnerable to attract plaque. This disadvantage may entail that in some patients inflammation around rougher-surfaced implants 
might occur easier. Some patient groups are more vulnerable for this than others, e.g., periodontally compromised patients and smokers. They tend to have a higher risk of implant failure [7-16]. Clinicians are commonly placing dental implants with various surface roughness and modifications including plasma-sprayed, acid-etched, blasted, oxidized, hydroxyapatite-coated, or combinations of these procedures in these risk groups $[17,18]$.

In their systematic review, Saffi et al. have stated that periodontally compromised patients were significantly at higher risk of implant failure and increased marginal bone loss compared with periodontally healthy patients [19]. The microbiotic flora involved in peri-implant disease, i.e., peri-implantitis, resembles the flora associated with periodontitis [20-22]. Teeth might act as a reservoir for the colonization of the peri-implant sulcus. Within 2 weeks after one-stage implant placement or abutment connection in a partially edentulous patient, the peri-implant sulcus becomes colonized with bacteria similar to the neighboring natural teeth [23]. However, several other studies have reported no association between failing implants and history of periodontal disease $[17,24,25]$. Another systematic review on implant treatment in periodontally compromised patients has demonstrated high survival rates of implants in individuals with a history of periodontitis-associated tooth loss [26].

Several animal studies have suggested that the roughness of the implant surface influences the progression of peri-implantitis and the outcome of peri-implantitis treatment [27-31]. There is some evidence in men showing that machined implants are less prone to peri-implantitis compared with implants with rougher surfaces [32]. Moreover, implants with a rough surface have higher rates of late implant failures compared with machined or moderately rough implants $[1,33]$. Concerning the peri-implantitis treatment, Esposito et al. have shown in a systematic review that the progressive marginal bone loss around rough implants may be more difficult to halt than around machined implants [34].

Therefore, the question arises as to whether periodontally compromised patients might benefit from placing machined implants, in spite of their relatively higher early failure rate [35]. Thus, the aim of this systematic review is to evaluate the effect of different implant surface roughness on implant survival rate, mean marginal bone loss, and the incidence of peri-implantitis in periodontally compromised patients. For this reason, the present review addresses the following PICO (patient-intervention-comparison-outcomes) question: Is there a difference for implant survival, mean marginal bone loss, and the incidence of bleeding on probing $(\mathrm{O})$ in periodontally compromised patients $(\mathrm{P})$ receiving a machined dental implant (I) or rough surface dental implant (C)? Preferably, this question is answered in randomized controlled trials.

\section{Methods}

This study followed the PRISMA statement guidelines and is registered at PROSPERO under registration code CRD42018093063. A review protocol does not exist.

\section{Search strategy}

The listed PICO question is used in the present systematic search strategy. The electronic data resources consulted were PubMed/MEDLINE and Cochrane Library, including all published clinical studies until May 2018. The results were limited to studies written in English.

The following terms were imported in the search strategy on PubMed/MEDLINE: dental AND (implant OR implants OR implantation OR implantology) AND (surface OR surfaces) AND (periodontics OR periodontology OR periodontal disease). The following terms were used in the search strategy on the Cochrane Library: ((((dental AND (implant) OR implants) OR implantation) OR implantology)) AND ((((surface) OR surfaces) OR surface topography)) AND (((periodontics) OR periodontology) OR periodontal disease).

\section{Inclusion and exclusion criteria}

Eligibility criteria included human randomized and non-randomized controlled trials and prospective and retrospective cohort studies. All periodontally compromised patients studied should be successfully periodontally treated and enrolled in a high-quality maintenance care program after completion of active treatment. At least ten patients had to be examined. Only studies with a follow-up of at least 3 years were included. Studies with orthodontic implants, immediate placed and/or loaded implants, and implants placed in combination with sinus floor elevation were excluded. Also, case reports, technical reports, animal studies, cadaver studies, in vitro studies, and review papers were rejected.

\section{Study selection}

Two reviewers (A.D. and A.T.) screened all identified titles and abstracts independently. In addition, the reference lists of the subsequently selected abstracts and the bibliographies of the systematic reviews were searched manually. For studies appearing to meet the inclusion criteria, or for which insufficient data in the title and abstract was available, the full text was obtained. Disagreements were solved through discussion between the authors. Finally, the full-text evaluation of the remaining publications was done using the above-listed inclusion and exclusion criteria.

\section{Data extraction and meta-analysis}

Two reviewers independently extracted data from the included studies. Disagreements were again resolved through discussion. Corresponding authors were contacted when 
data were incomplete or unclear. With respect to the listed PICO question, data were sought for (P) periodontally compromised and patients without a history of periodontitis receiving dental implant placement, (I) machined surface dental implants, and $(\mathrm{C})$ rough surface dental implants. Both reviewers evaluated the following primary outcomes $(\mathrm{O})$ : implant survival rate after 3-10 years and implant mean marginal bone loss. Implant mean attachment loss, incidence of peri-implantitis, and incidence of bleeding on probing around implants were evaluated as secondary outcomes. Meta-analysis was attempted for studies reporting the same outcome measures. Finally, funding sources of the selected studies have been checked.

\section{Quality of the studies}

Quality assessment of the selected studies was executed by using the Cochrane Collaboration Tool (http://ohg.cochrane.org) for randomized controlled trials (RCTs) including random sequence generation, allocation concealment, blinding of participants, incomplete outcome data, selective reporting, and other bias. The Newcastle-Ottawa scale (http://www.ohri.ca/programs/clinical_epidemiology/ oxford.asp) was applied for non-randomized studies to judge each included study on selection of studies, comparability of cohorts, and the ascertainment of either the exposure or outcome of interest. Stars were awarded such that the highest quality studies were awarded up to nine stars.

\section{Statistical analysis}

Review Manager 5.0 was used for statistical analysis. Differences in means and risk ratios were used as principal summary measures. Forest plots were created to visualize the differences between groups.

\section{Results}

The initial electronic database search on PubMed/MEDLINE and Cochrane library resulted in 2411 titles. Thirteen articles were cited in both databases (duplicates). After screening the abstracts, 45 relevant titles were selected by two independent reviewers and 2353 were excluded for not being related to the topic. Following examination and discussion by the reviewers, 43 articles were selected for full-text evaluation. Hand searching of the reference lists of the selected studies did not deliver additional papers. After pre-screening, application of the inclusion and exclusion criteria and handling of the PICO questions, six studies remained (ten studies did not report on a periodontally compromised group, two studies did not on a periodontally healthy group, one paper reported only on immediate loading, one paper only on immediate restoration, two studies only inform on micro-implants, two were microbiological studies, in eleven studies the periodontal status was not mentioned, five studies only reported on moderate rough implants, one only on machined surface implants, one paper did not report on primary outcome mean marginal bone loss, and from one paper only the article with 5-year results was included, while the corresponding article with 20-year results was excluded) [36-41]. They were used for data extraction and statistical analysis. Of the six included studies, two were RCTs [38, 40]. Figure 1 illustrates a flowchart of the search results.

\section{Study characteristics}

Within the remaining group of six included studies in one study, $5.3 \%$ of the patients have controlled diabetes mellitus (Gallego et al.) [41]. With this exception, all patients were generally and periodontally healthy at the moment of implantation (Table 1). Four out of the six studies looked only at periodontally compromised patients (Sayardoust et al., Wennström et al., Nicu et al., and Gallego et al.), whereas the other two looked both at periodontally healthy patients and periodontally compromised patients (Aglietta et al. and Matarasso et al.) [36-41]. One study contained only smokers (Aglietta et al.), one study contained only non-smokers (Matarasso et al.), another study made separate groups for smokers and non-smokers (Sayardoust et al.), and three studies mixed both smokers and non-smokers (Wennström et al., Nicu et al., and Gallego et al.) [36-41]. Different periodontal diagnoses were reported within the periodontally compromised patient group: mild, chronic, moderate, and advanced. Two studies did not report on the use of antibiotics (Aglietta et al., Matarasso et al.) [36, 39]. In one study, no antibiotics were used (Sayardoust et al.) [37]. In the study of Nicu and coworkers, post-operative antibiotics were prescribed: $3 \times 500 \mathrm{mg}$ amoxicillin, 5 days [40]. In the study of Wennström and coworkers, the patient received $2 \mathrm{~g}$ of penicillin $1 \mathrm{~h}$ pre-operatively and $2 \times 1 \mathrm{~g}$ penicillin, 7 days post-operatively [38]. In the study protocol of Gallego and coworkers, $3 \times 500 \mathrm{mg}$ amoxicillin for 7 days was prescribed [41].

There is some variation in the follow-up between the different studies. Two studies had a follow-up of 5 years (Sayardoust et al. and Wennström et al.), two had a follow-up of 10 years (Aglietta et al. and Matarasso et al.), and for two studies, it was 3 years (Nicu et al. and Gallego et al.) [36-41]. All included periodontally compromised patients participated in a regular periodontal maintenance program. The mean age in the six included studies containing 555 patients ranged from 46.5 to 63.2 years. Both partially and fully edentulous patients were included, and implants were placed in both the maxilla and the mandible in five studies [36-40]. In one study (Gallego et al.), implants were exclusively placed in the posterior mandible [41]. In three studies, all implants 


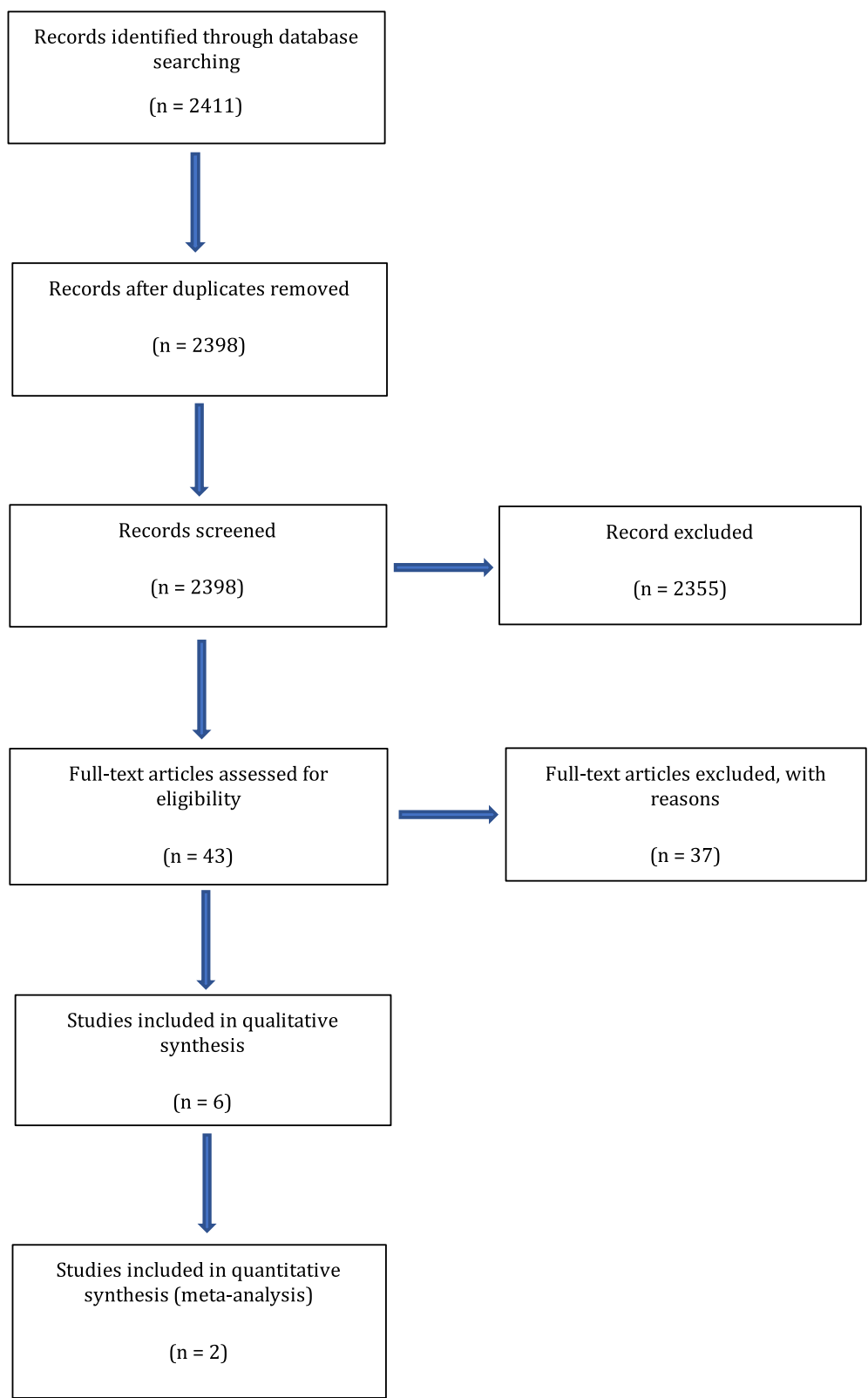

Fig. 1 Flowchart of the search strategy

were placed two-staged (Sayardoust et al., Wennström et al., and Nicu et al.), and in two studies, only machined implants were placed two-staged (Aglietta et al. and Matarasso et al.) [36-40].

\section{Results of the individual studies}

As measured in the six included studies containing 1342 implants, implant survival rates for machined surface implants ranged from 84.9 to $97.1 \%$, while for rough surface implants ranged from 80 to $100 \%$ (Table 1). Machined surface implants display a range from 0.33 (CI $95 \%-0.74,1.40)$ to 3.47 (CI 95\% 2.38, 5.46) for implants mean marginal bone loss, while rough surface implants display a range from 0.48 (CI $95 \%-0.47,1.43$ ) to 3.77 (CI 95\% 2.34, 5.20). Bleeding on probing varies from 5.0 to $69 \%$ [36-41].

\section{Quality of the studies}

Quality assessment of the included prospective studies was executed according to the Newcastle-Ottawa scale. The two studies were of moderate quality, and risk of bias is present in both $[38,40]$. In Wennström et al., we accounted several losses to follow-up: three patients had died and one patient had discontinued therapy [38]. 


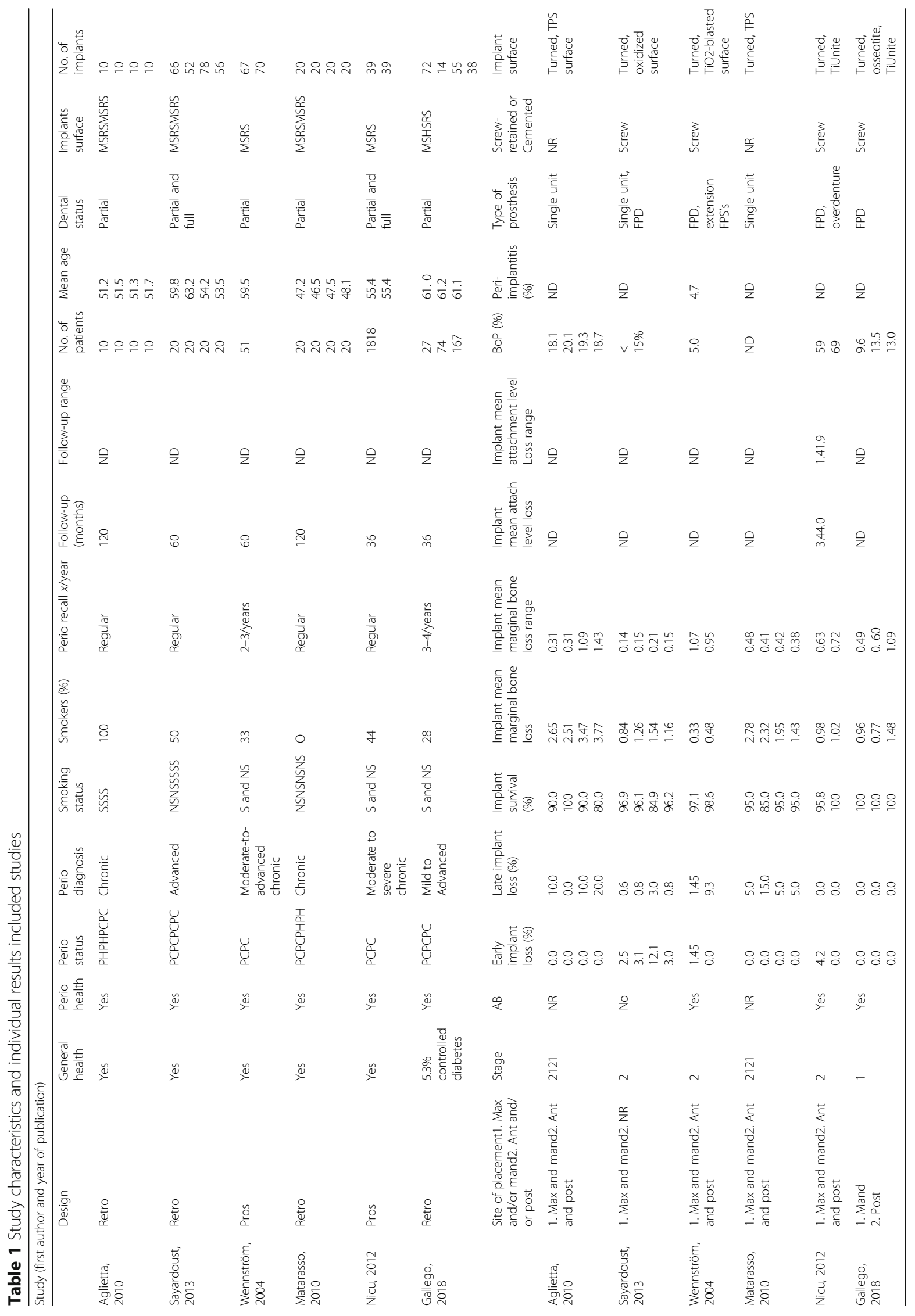


Each patient received a minimum of two implants, and by randomization, every second implant inserted had a machined surface and the remaining had a rough surface. The absence of a split-mouth design creates a risk of bias because the evaluated groups are not completely comparable. The authors accomplish concealment of allocation by proper blinding using a randomization code which was made available after the surgeon had made his osteotomies. Clinical scores were assessed by an examiner not involved in the trial. In our validity assessment, we found that the Nicu et al. paper is at high risk of bias [40]. The extra groove in the TiUnite implants precluded proper blinding, although both implant types had the same macro design. In every patient, two or more machined surface implants and two or more rough surface implants were randomly selected by a computer randomization program. Figure 2a, b displays assessment of the risk of bias for included RCT and non-RCT studies.

\section{Synthesis of results}

Figure 3 illustrates a forest plot showing no significant differences in implant survival between MS and RS groups in all included studies [36-41]. The implant mean marginal bone loss in the remaining group of six included studies containing 1342 implants ranged from 0.33 to $3.77 \mathrm{~mm}$, with a minimum and maximum of -0.74 and $5.20 \mathrm{~mm}$, respectively [36-41]. The forest plot in Fig. 4 demonstrates no significant differences in implant mean marginal bone loss between MS and RS groups in all included studies [36-41]. One study (Matarasso et al.) did not report on bleeding on probing $(\mathrm{BoP})$, whereas four studies reported BoP varying from 5.0 to $69.0 \%$ (Aglietta et al., Sayardoust et al., Wennström et al., Nicu et al., and Gallego et al.) [36-41]. Meta-analysis was in addition separately performed on the two included RCTs [38.40]. Figure 5 illustrates a forest plot showing no significant differences $(P>.05)$ in implant survival between MS and RS groups in both studies [38, 40]. Figure 6 shows no significant differences $(P>.05)$ in implant mean marginal bone loss between MS and RS groups in both RCTs $[38,40]$. A limitation of the performed meta-analysis is that the merge of periodontally compromised smokers and non-smokers could not be avoided.

\section{(a)}

\begin{tabular}{|l|c|c|}
\hline $\begin{array}{l}\text { Random sequence } \\
\text { generation }\end{array}$ & + & \\
\hline Allocation concealment & + & \\
\hline $\begin{array}{l}\text { Blinding of participants } \\
\text { and personnel }\end{array}$ & & \\
\hline Incomplete outcome data & ( & \\
\hline Selective reporting & + & \\
\hline Other bias & $?$ & ? \\
\hline & $\begin{array}{c}\text { Wennström et al. } \\
\text { (2004) }\end{array}$ & Nicu et al. (2012) \\
\hline
\end{tabular}

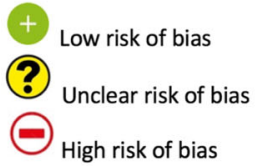

n.a. Not applicable

(b)

\begin{tabular}{|l|c|c|c|}
\hline & $\begin{array}{c}\text { Selection } \\
\text { (max.4 stars) }\end{array}$ & $\begin{array}{c}\text { Comparability } \\
\text { (max. 2 stars) }\end{array}$ & $\begin{array}{c}\text { Outcome } \\
\text { (max.4 stars) }\end{array}$ \\
\hline Aglietta et al. (2010) & - & - & \\
\hline Sayardoust et al. (2013) & & - & \\
\hline Matarasso et al. (2010) & - & \\
\hline Gallego et al. (2018) & - &
\end{tabular}

Fig. 2 a Presentation of risk of bias evaluation for included RCTs according to the Cochrane Collaboration's tool. b Presentation of risk of bias evaluation for included non-RCTs according to the Newcastle-Ottawa assessment scale 


\begin{tabular}{|c|c|c|c|c|c|c|c|c|c|c|}
\hline Study or Subgroup & \multicolumn{2}{|l|}{ MS } & RS & Total & Weight & $\begin{array}{c}\text { Risk Ratio } \\
\text { M-H, Random, 95\% Cl }\end{array}$ & \multicolumn{4}{|c|}{$\begin{array}{c}\text { Risk Ratio } \\
\text { M-H, Random, } 95 \% \mathrm{Cl}\end{array}$} \\
\hline Aglietta et al. (2010) & 1 & 10 & 2 & 10 & $20.7 \%$ & $0.50[0.05,4.67]$ & & & & \\
\hline Gallego et al. (2018) & 0 & 27 & 0 & 167 & & Not estimable & & & & \\
\hline Matarasso et al (2010) & 1 & 20 & 3 & 20 & $21.8 \%$ & $0.33[0.04,2.94]$ & & & & \\
\hline Nicu et al. (2003) & 2 & 39 & 0 & 39 & $11.4 \%$ & $5.00[0.25,100.89]$ & & & & \\
\hline Sayadoust et al. (2013) & 2 & 66 & 2 & 52 & $27.8 \%$ & $0.79[0.11,5.41]$ & & & & \\
\hline Wennström et al. (2004) & 2 & 67 & 1 & 70 & $18.3 \%$ & $2.09[0.19,22.51]$ & & & - & \\
\hline Total $(95 \% \mathrm{Cl})$ & & 229 & & 358 & $100.0 \%$ & $0.88[0.32,2.42]$ & & & & \\
\hline Total events & 8 & & 8 & & & & & & & \\
\hline $\begin{array}{l}\text { Heterogeneity: } \operatorname{Tau}^{2}=0.0 \\
\text { Test for overall effect: } Z=\end{array}$ & $\begin{array}{l}\mathrm{Chi}^{2}=2 \\
25(\mathrm{P}=\mathrm{l}\end{array}$ & $\begin{array}{l}84, \mathrm{df}= \\
1.80)\end{array}$ & $=4\langle P=0$ & $.58) ; 1^{z}$ & $=0 \%$ & & 0.01 & $\begin{array}{l}0.1 \\
\text { Favours [MS] }\end{array}$ & $\begin{array}{r}10 \\
\text { Favours [RS] }\end{array}$ & 100 \\
\hline
\end{tabular}

Fig. 3 Forest plot on differences in implant survival between MS and RS groups in all included studies

\section{Discussion}

The current study reviews the literature on the effect of dental implant surfaces in patients with a history of periodontal disease. The six included papers comprised both retrospective and prospective studies [36-41]. The two prospective randomized clinical trials were analyzed separately $[38,40]$. As demonstrated by equality of the risk ratios and on account of the limited amount of included studies, we could not find any difference between machined surface implants and rough surface implants in both implant survival rate and implant mean marginal bone loss.

All treated patients were periodontally healthy before they took part in the actual investigations. It is widely clinically accepted that, in periodontally compromised patients, implants are only placed after successful periodontal therapy. Already in the nineties, it has been proved that individuals with a strong susceptibility to periodontal diseases can be treated successfully with osseointegrated implants [42]. Moreover, Meyle et al. have recently demonstrated stable clinical and radiographic implant results in patients with a previous history of periodontitis [43]. On the other hand, it is known that patients with a history of periodontitis yield lower survival, significantly higher complications, and significantly lower success rates compared with patients who had lost their teeth for reasons other than periodontitis [44, 45]. Heitz-Mayfield and Huynh-Ba have shown in a review that the combination of a previous experience of periodontal disease and smoking increases the risk of implant failure and marginal bone loss around implants [46]. The present review reports on chronic, moderate, and advanced periodontitis. This implies that the compromising condition for all these periodontal subgroups is comparable. However, it is likely that, in this way, a bias is introduced. Indeed, Mengel and Flores-de-Jakoby have shown that patients treated for generalized aggressive periodontitis experience more attachment loss and bone loss when compared with patients treated for chronic periodontitis [47]. In addition, these patients are clearly more prone to late failure [47]. Similar findings have been reported by De Boever et al. who have shown that, unlike patients with chronic adult periodontitis, patients with generalized aggressive periodontitis exhibit more peri-implant pathology and marginal bone loss and display lower implant survival rates [48]. In accordance with the manufacturer's instructions, all turned surface implants in this review were placed in the classic Bränemark two-stage submerged protocol, while the other implants were placed non-submerged. Recent studies have shown comparable outcomes for both treatment modalities $[49,50]$.

Bias is present in the included papers, and this can have a substantial impact on our findings. For example,

\begin{tabular}{|c|c|c|c|c|c|c|c|c|c|c|}
\hline \multirow[b]{2}{*}{ Study or Subgroup } & \multicolumn{3}{|c|}{ MS } & \multicolumn{3}{|c|}{ RS } & \multirow[b]{2}{*}{ Weight } & \multirow{2}{*}{$\begin{array}{l}\text { Mean Difference } \\
\text { IV, Random, 95\% CI }\end{array}$} & \multirow{2}{*}{$\begin{array}{l}\text { Mean Difference } \\
\text { IV, Random, 95\% CI }\end{array}$} & \\
\hline & Mean & SD & Total & Mean & SD & Total & & & & \\
\hline Aglietta et al. (2010) & 3.47 & 1.09 & 10 & 3.77 & 1.43 & 10 & $5.7 \%$ & $-0.30[-1.41,0.81]$ & & \\
\hline Gallego et al. (2018) & 0.96 & 0.49 & 27 & 1.48 & 1.09 & 167 & $19.0 \%$ & $-0.52[-0.77,-0.27]$ & & \\
\hline Matarasso et al. (2010) & 2.78 & 0.48 & 20 & 2.32 & 0.41 & 20 & $18.5 \%$ & $0.46[0.18,0.74]$ & & \\
\hline Nicu et al. (2003) & 0.98 & 0.63 & 39 & 1.02 & 0.72 & 39 & $18.0 \%$ & $-0.04[-0.34,0.26]$ & & \\
\hline Sayadoust et al. (2013) & 0.84 & 0.14 & 66 & 1.26 & 0.15 & 52 & $21.6 \%$ & $-0.42[-0.47,-0.37]$ & & \\
\hline Wennström et al. (2004) & 0.33 & 1.07 & 67 & 0.48 & 0.95 & 70 & $17.2 \%$ & $-0.15[-0.49,0.19]$ & & \\
\hline Total $(95 \% \mathrm{Cl})$ & & & 229 & & & 358 & $100.0 \%$ & $-0.15[-0.46,0.15]$ & & \\
\hline $\begin{array}{l}\text { Heterogeneity: } \operatorname{Tau}^{2}=0.1 \\
\text { Test for overall effect: } Z=\end{array}$ & $\begin{array}{l}\mathrm{Chi}^{2}= \\
.98(\mathrm{P}=\end{array}$ & $\begin{array}{l}45.54, \\
0.33)\end{array}$ & $d f=5(f$ & $P=0.00$ & 0001): & $F^{2}=899$ & & -100 & $\begin{array}{lrr}1 & 1 \\
-50 & 0 & 50 \\
\text { Favours [MS] } & \text { Favours [RS] }\end{array}$ & 100 \\
\hline
\end{tabular}

Fig. 4 Forest plot on differences in implant mean marginal bone loss between MS and RS groups in all included studies 


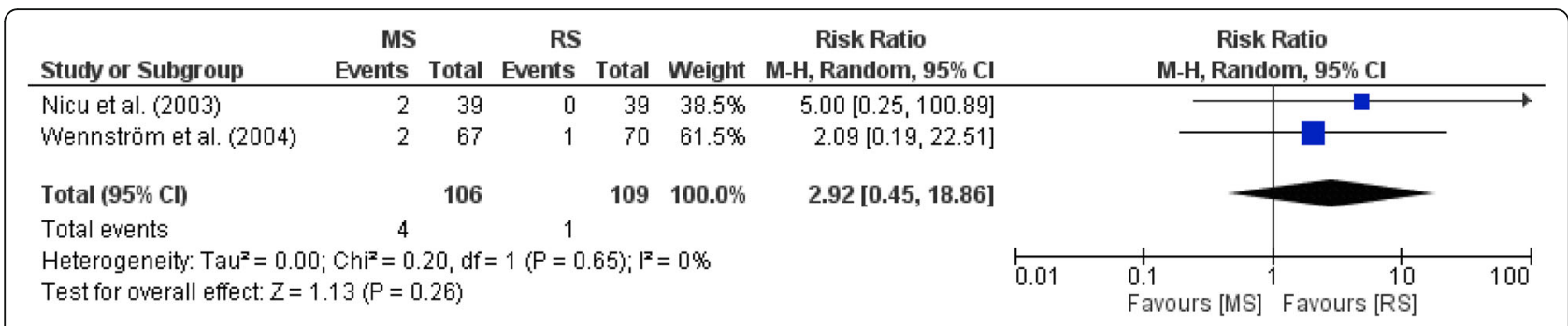

Fig. 5 Forest plot on differences in implant survival between MS and RS groups in all included RCT's

in the studies by Wennström et al. and Nicu et al., smoking is a confounding factor, since both non-smokers and smokers have been combined [38, 40]. However, Cavalcanti et al. have performed a retrospective multicenter cohort study and have demonstrated almost twice as many implant failures in smokers compared with non-smokers [51]. Others have reported that smoking is a significant risk factor for early implant failures [52]. Subsequently, Sayardoust et al. and Nicu et al. have included fully edentulous patients in addition to partially edentulous patients $[37,40]$. In the latter, the remaining dentition was able to serve as a source of pathogens, unlike the edentulous patients where prominent pathogens disappeared following dental extraction $[20,53,54]$. Another confounding factor could be the different sites of placement in the mouth. The loading of the implants differs between the anterior and posterior areas, and this could play a role in the measured outcomes [55]. Furthermore, bone quality is different between the maxilla and the mandible. Although implants have been installed arbitrarily in both jaws, more bone loss in the maxilla has been reported in clinical follow-up studies, without a real explanation for this phenomenon [56]. It is worth to note that all implants inserted in the reviewed papers have been placed in areas with good bone quality and under ideal conditions (e.g., implant placement predominantly in pristine cortical bone; Lekholm and Zarb type I and II bones). Indeed, under these conditions, one may expect a difficulty in detecting any differences due to the surface characteristics. Differences are more likely to be detected under conditions which are less ideal. The prescription of antibiotics is another potential confounding factor
(Additional files 1, 2, 3, and 4). Two of the selected studies did not report on the intake of this prophylactic medicine [36, 39]. Keenan and Veitz-Keenan have recently suggested in their systematic review that a prophylactic antibiotic regimen reduces the failure of dental implants placed under ordinary conditions [57]. The osseointegrated implants have been provided with single unit crowns or fixed partial dentures. Only Nicu et al. have also included overdenture patients in their study [40]. Another important item that has not been addressed in any of the selected studies is the way in which the implant-supported restorations were connected to the fixture. In a recent systematic review, Lemos et al. have indicated that cement-retained, fixed implant-supported restorations show less marginal bone loss, fewer prosthetic complications, and higher implant survival rates compared with screw-retained, fixed implant-supported restorations [58]. However, this review should be interpreted with caution because of the few RCTs included in the analysis and the maximum observation time of 5 years of these meta-analyzed studies. The occurrence of peri-implantitis was reported in only one out of the six studies. Wennström et al. have reported a total of $4.7 \%$ peri-implantitis in the entire patient population [38]. The list of the six articles included five different surfaces. Machined implants are considered to be minimal rough [2]. In the moderately rough group, a significant heterogeneity has been observed: titanium plasma-sprayed, oxidized, titanium dioxide-blasted, and TiUnite-surfaces with different characteristics. The authors excluded the Donati et al. 20-year results of the Wennström et al. paper because of heterogeneity in follow-up time [59].

\begin{tabular}{|c|c|c|c|c|c|c|c|c|c|c|c|}
\hline \multirow[b]{2}{*}{ Study or Subgroup } & \multicolumn{3}{|c|}{ MS } & \multicolumn{3}{|c|}{ RS } & \multicolumn{3}{|c|}{ Mean Difference } & \multirow{2}{*}{$\begin{array}{c}\text { Mean Difference } \\
\text { IV, Random, } 95 \% \mathrm{Cl}\end{array}$} & \\
\hline & Mean & SD & Total & Mean & SD & Total & Weight & IV, Random, 95\% Cl & & & \\
\hline Nicu et al. (2003) & 0.98 & 0.63 & 39 & 1.02 & 0.72 & 39 & $56.1 \%$ & $-0.04[-0.34,0.26]$ & & $I$ & \\
\hline Wennström et al. (2004) & 0.33 & 1.07 & 67 & 0.48 & 0.95 & 70 & $43.9 \%$ & $-0.15[-0.49,0.19]$ & & 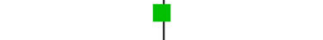 & \\
\hline Total $(95 \% \mathrm{Cl})$ & & & 106 & & & 109 & $100.0 \%$ & $-0.09[-0.31,0.14]$ & & & \\
\hline \multicolumn{7}{|c|}{$\begin{array}{l}\text { Heterogeneity: Tau }=0.00 ; \mathrm{Chi}^{2}=0.23, \mathrm{df}=1(\mathrm{P}=0.63) ; \mathrm{I}^{2}=0 \% \\
\text { Test for overall effect: } Z=0.77(P=0.44)\end{array}$} & & & -100 & $\begin{array}{llr}1 & 1 & 1 \\
-50 & 0 & 50 \\
\text { Favours [MS] } & \text { Favours [RS] }\end{array}$ & 100 \\
\hline
\end{tabular}


Further aspects that could contribute to bias are methodological factors. A risk of an overestimation exists due to analyzing the data on the implant level rather than the patient level, which is the result of the larger number of implants placed.

The heterogeneity and the variability in the study designs, together with the fact that most previous studies have not reported on confounding factors, make it difficult to draw definitive conclusions. In addition, the broad confidence intervals provide an uncertain outcome. In spite of their relatively higher failure rate, machined implants have possible advantages on the long term, because they attract less plaque once they become exposed after some years. Jungner et al. have shown equally high long-term survival rates, stable marginal and apical bone levels, and good peri-implant soft tissue health for turned and oxidized implants placed in grafted maxillary sinus floors [60]. Previous reviews by Quirynen et al. and Esposito et al. have shown a tendency towards more bone loss and higher incidence of implant loss around rougher surface implants [1, 34]. In an updated review on 27 randomized controlled trials in 1512 patients and 3230 implants, Esposito et al. have reported no evidence of a link between the type of dental implants and improved long-term success [61]. Simultaneously, they have stated that some limited evidence is present showing that implants with machined surface were less prone to bone loss related to peri-implantitis compared with implants with rougher surfaces. In a recent review, Doornewaard et al. have reported that peri-implant bone loss around machined implant systems was significantly lower than around moderately rough and rough implant systems [62]. However, they have concluded that the impact of surface roughness alone seems rather limited and of minimal clinical relevance.

\section{Conclusions}

Due to lack of long-term data ( $>5$ years), the heterogeneity and variability in study designs and lack of reporting on confounding factors, definitive conclusions on differences in implant survival, and mean marginal bone loss between machined and moderate rough implants in periodontally compromised patients cannot be drawn. In order to understand whether or not machined surfaces are superior to moderately rough surfaces in patients with a history of periodontal disease, well-designed long-term randomized controlled trials are needed.

\section{Additional files}

Additional file 1: Conflict of interest form (PDF $569 \mathrm{~kb}$ )

Additional file 2: Conflict of interest form (PDF $1224 \mathrm{~kb}$ )

Additional file 3: Conflict of interest form (PDF $569 \mathrm{~kb}$ )
Additional file 4: Conflict of interest form (PDF $569 \mathrm{~kb}$ )

\section{Abbreviations}

AE: Acid-etched; Ant: Anterior; FPD: Fixed partial denture; Full: Fully edentulous; HA: Hydroxyl apatite; HS: Hybrid surface; Mand: Mandible; Max: Maxilla; MS: Machined surface; ND: No data; NR: Not reported; NS: Nonsmoking; Partial: Partially edentulous; PC: Periodontally compromised patient; PH: Periodontally healthy patient; Post: Posterior; Pros: Prospective; Retro: Retrospective; RS: Rough surface; S: Smoking; SLA: Sandblasted acidetched; TPS: Titanium plasma sprayed

\section{Acknowledgements}

The authors would like to thank Dr. Elena Nicu for providing missing information about her study.

\section{Funding}

None.

Availability of data and materials

This paper is distributed under the terms of the Creative Commons Attribution 4.0 International License, which permits unrestricted use, distribution, and reproduction in any medium, provided the author gives appropriate credit to the original author(s) and the source, provide a link to the Creative Commons License, and indicate if changes were made.

\section{Authors' contributions}

$A D, I H A A, D W$, and AT provided substantial contributions to the conception or design of the work, or the acquisition, analysis, or interpretation of data for the work; drafted the paper or revised it critically; gave final approval of the version to be published; and agreed to be accountable for all aspects of the work in ensuring that questions related to accuracy or integrity of any parts of the work are appropriately investigated and resolved.

\section{Ethics approval}

Not applicable.

\section{Consent for publication}

All authors read and approved the final manuscript.

\section{Competing interests}

Anton Dank, Irene H.A. Aartman, Daniël Wismeijer, and Ali Tahmaseb declare that they have no competing interests (Additional files 1, 2, 3 and 4).

\section{Publisher's Note}

Springer Nature remains neutral with regard to jurisdictional claims in published maps and institutional affiliations.

\section{Author details}

${ }^{1}$ Section of Oral Implantology and Prosthetic Dentistry, Academic Centre for Dentistry Amsterdam (ACTA), University of Amsterdam and Vrije Universiteit Amsterdam, Gustav Mahlerlaan 3004, 1081 LA Amsterdam, The Netherlands. ${ }^{2}$ Department of Social Dentistry, Academic Centre for Dentistry Amsterdam (ACTA) University of Amsterdam and Vrije Universiteit Amsterdam, Gustav Mahlerlaan 3004, 1081 LA Amsterdam, The Netherlands.

Received: 14 August 2018 Accepted: 6 January 2019

Published online: 13 February 2019

\section{References}

1. Quirynen M, Abarca M, Van Assche N, Nevins M, Van Steenberghe D. Impact of supportive periodontal therapy and implant surface roughness on implant outcome in patients with a history of periodontitis. J Clin Periodontol. 2007;34:805-15.

2. Albrektsson T, Wennerberg A. Oral implant surfaces: part 1-review focusing on topographic and chemical properties of different surfaces and in vivo responses to them. Int J Prosthodont. 2004;17:536-63.

3. Wennerberg A, Hallgren C, Jahonsson C, Danelli S. A histomorphometric evaluation of screw-shaped implants each prepared with two surface roughnesses. Clin Oral Implants Res. 1998;9:11-9. 
4. Cochran DL. A comparison of endosseous dental implant surfaces. J Periodontol. 1999;70:1523-39.

5. Lazzara RJ, Testori T, Trisi P, Porter SS, Weinstein RL. A human histologic analysis of osseotite and machined surfaces using implants with two opposing surfaces. Int J Periodontics Restorative Dent. 1999;19:117-29.

6. Teughels W, Van Assche N, Sliepen I, Quirynen M. Effect of material characteristics and/or surface topography on biofilm development. Clin Oral Implants Res. 2006;17:68-81.

7. Bain CA, Moy PK. The association between the failure of dental implants and cigarette smoking. Int J Oral Maxillofac Implants. 1993;8:609-15.

8. Brocard D, Barthet P, Baysse E, Duffort JF, Eller P, Justumus P. A multicenter report on 1.022 consecutively placed ITI implants: a 7-year longitudinal study. Int J Oral Maxillofac Implants. 2000;15:691-700.

9. De Bruyn H, Collaert B. The effect of smoking on early implant failure. Clin Oral Implants Res. 1994;5:260-4.

10. Karoussis IK, Kotsovilis S, Fourmousis I. A comprehensive and critical review of dental implant prognosis in periodontally compromised partially edentulous patients. Clin Oral Implants Res. 2007;18:669-79.

11. Schwartz-Arad D, Samet N, Samet N, Mamlider A. Smoking and complications of endosseous dental implants. J Periodontol. 2002;73:153-7.

12. Van der Weijden GA, Van Bemmel KM, Renvert S. Implant therapy in partially edentulous, periodontally compromised patients: a review. J Clin Periodontol. 2005;32:506-11.

13. Bealum V, Ellegaard B. Implant survival in periodontally compromised patients. J Periodontol. 2004;75:1404-12.

14. Rosenberg ES, Dent HD, Cho S, Elian N, Jalbout ZN, Froum S. A comparison of characteristics of implant failure and survival in periodontally compromised and periodontally healthy patients: a clinical report. Int J Oral Maxillofac Implants. 2004;19:873-9.

15. Balshe AA, Eckert SE, Koka S, Assad DA, Weaver AL. The effects of smoking on the survival of smooth- and rough-surface dental implants. Int J Oral Maxillofac Implants. 2008;23:1117-22.

16. Hinode D, Tanabe S, Yokoyama M, Fujisawa K, Yamauchi E, Miyamto Y. Influence of smoking on osseointegrated implant failure: a meta-analysis. Clin Oral Implants Res. 2006;17:473-8.

17. Bain CA, Weng D, Meltzer A, Kohles SS, Stach RM. A meta-analysis evaluating the risk for implant failure in patients who smoke. Compend Contin Educ Dent. 2002;23:695-709.

18. Garcia-Bellosta S, Bravo M, Subira C, Echeveria JJ. Retrospective study of the long-term survival of 980 implants placed in a periodontal practice. Int J Oral Maxillofac Implants. 2010;25:613-9.

19. Saffi SH, Palmer RM, Wilson RF. Risk of implant failure and marginal bone loss in subjects with a history of periodontitis: a systematic review and meta-analysis. Clin Implant Dent Relat Res. 2010;12:165-74.

20. Apse P, Ellen RP, Overall CM, Zarb GA. Microbiota and crevicular fluid collagenase activity in the osseointegrated dental implant sulcus: a comparison of sites in edentulous and partially edentulous patients. J Periodontal Res. 1989;24:96-105.

21. Mombelli A, Lang NP. The diagnosis and treatment of peri-implantitis. Periodontology 2000. 1998;17:63-76.

22. Quirynen M, Teughels W. Microbiologically compromised patients and impact on oral implants. Periodontol 2000. 2003;33:119-28.

23. De Boever AL, De Boever JA. Early colonization of non-submerged dental implants in patients with a history of advanced aggressive periodontitis. Clin Oral Implants Res. 2006;7:8-17.

24. Klokkevold PR, Han TJ. How do smoking, diabetes, and periodontitis affect outcomes of implant treatment. Int J Oral Maxillofac Implants. 2007;22:173-202.

25. Schou S. Implant treatment in periodontitis-susceptible patients: a systematic review. J Oral Rehabil. 2008;35:9-22

26. Kumar A, Jaffin RA, Berman C. The effect of smoking on achieving osseointegration of surface-modified implants: a clinical report. Int I Oral Maxillofac Implants. 2002;17:816-9.

27. Albouy JP, Abrahamsson I, Persson LG, Berghlundh T. Spontaneous progression of peri-implantitis of different types of implants: an experimental study in dogs. I: clinical and radiographic observations. Clin Oral Implants Res. 2008;19:997-1002.

28. Albouy JP, Abrahamsson I, Berglundh T. Spontaneous progression of experimental peri-implantitis at implants with different surface characteristics: an experimental study in dogs. J Clin Periodontol. 2012; 9:182-7.
29. Berglundh T, Gotfredsen K, Zitzman NU, Lang NP, Lindhe J. Spontaneous progression of ligature induced peri-implantitis at implants with different surface roughness: an experimental study in dogs. Clin Oral Implants Res. 2007;18:655-61.

30. Martines RT, Sendyk WR, Gromatzky W, Cury PR. Sandblasted/acid-etched vs smooth surface implants: implant clinical reaction to experimentally induced peri-implantitis in Beagle dogs. J Oral Implantol. 2008;34:185-9.

31. Albouy JP, Abrahamsson I, Persson LG, Berglundh T. Implant surface characteristics influence the outcome of treatment of peri-implantitis: an experimental study in dogs. J Clin Periodontol. 2011;38:58-64.

32. Esposito M, Coulthard $\mathrm{P}$, Thomsen $\mathrm{P}$, Worthington HV. The role of implant surface modifications, shape and material on the success of osseointegrated dental implants. A Cochrane systematic review. Eur J Prosthodont Restor Dent. 2005;13:15-31.

33. Becker $\mathrm{W}$, Bahat $\mathrm{O}$, Israelson $\mathrm{H}$. Re: a comparison of endosseous dental implant surfaces. J Periodontol. 2000;71:1053-6.

34. Esposito M, Murray-Curtis L, Grusovin MG, Patel S, Coulthard P, Worthington HV. Interventions for replacing missing teeth: different types of dental implants. Cochrane Database Syst Rev. 2007;17:CD003815.

35. Cochran DL. Implant therapy I. Ann Periodontol. 1996;1:707-91.

36. Aglietta M, Siciliano VI, Rasperini G, Cafiero C, Lang NP, Salvi GE. A 10-year retrospective analysis of marginal bone-level changes around implants in periodontally healthy and periodontal compromised tobacco smokers. Clin Oral Implants Res. 2011;22:47-53.

37. Sayardoust S, Gröndahl K, Johansson E, Thomsen P, Slotte C. Implant survival and marginal bone loss at turned and oxidized implants in periodontitis-susceptible smokers and never-smokers: a retrospective, clinical, radiographic case-control study. J Periodontol. 2013;84:1775-82.

38. Wennström JL, Ekestubbe A, Gröndahl K, Karlsson S, Lindhe J. Oral rehabilitation with implant-supported fixed partial dentures in periodontitissusceptible subjects. J Clin Periodontol. 2004;31:713-24.

39. Matarasso S, Rasperini G, Siciliano V, Salvi GE, Lang NP, Aglietta M. A 10-year retrospective analysis of radiographic bone-level changes of implants supporting single-unit crowns in periodontally compromised vs. periodontally healthy patients. Clin Oral Implants Res. 2010;21:898-903.

40. Nicu EA, Van Assche N, Coucke W, Teughels W, Quirynen M. RCT comparing implants with turned and anodically oxidized surfaces. J Clin Periodontol. 2012:39:1183-90.

41. Gallego L, Sicilia A, Sicilia P, Mallo C, Cuesta S, Sanz M. A retrospectieve study on the crestal bone loss associated with different implant surfaces in chronic periodontitis patients under maintenance. Clin Oral Implants Res. 2018;29(6):557-67.

42. Nevins M, Langer B. The successful use of osseointegrated implants for the treatment of the recalcitrant periodontal patient. J Periodontol. 1995:66:150-7.

43. Meyle J, Gersok G, Boedeker RH, Gonzales JR. Long-term analysis of osseointegrated implants in non-smoker patients with a previous history of periodontitis. J Clin Periodontol. 2014;41:504-12.

44. Karoussis IK, Salvi GE, Heitz-Mayfield LJ, Brägger U, Hammerle CH, Lang NP. Long-term implant prognosis in patients with and without a history of chronic periodontitis: a 10-year prospective cohort study of the ITI dental implant system. Clin Oral Implants Res. 2003;14:329-39.

45. Hardt CR, Gröndahl K, Lekholm U, Wennström JL. Outcome of implant therapy in relation to experienced loss of periodontal bone support. Clin Oral Implants Res. 2002;13:488-94.

46. Heitz-Mayfield LJ, Huynh-Ba G. History of treated periodontitis and smoking as risk for implant therapy. Int J Oral Maxillofac Implants. 2009;24:39-68.

47. Mengel R, Flores-de-Jacoby L. Implants in patients treated for generalized aggressive and chronic periodontitis: a 3-year prospective longitudinal study. J Periodontol. 2005;76:534-43.

48. De Boever AL, Quirynen M, Coucke W, Theuniers G, De Boever JA. Clinical and radiographic study of implant treatment outcome in periodontally susceptible and non-susceptible patients: a prospective long-term study. Clin Oral Implants Res. 2009;20:1341-50.

49. Nemli SK, Güngör MB, Aydin C, Yilmaz H, Türkcan I, Demirköprülü H. Clinical evaluation of submerged and non-submerged implants for posterior singletooth replacements: a randomized split-mouth clinical trial. Int J Oral Maxillofac Surg. 2014;43:1484-92.

50. Sánchez-Siles M, Munoz-Cámara D, Salazar-Sánchez N, Camacho-Alonso F, Calvo-Guirado JL. Crestal bone loss around submerged and non-submerged implants during the osseointegration phase with different healing 
abutment designs: a randomized prospective clinical study. Clin Oral Implants Res. 2016;10:1111-5.

51. Cavalcanti R, Oreglia F, Manfredonia MF, Gianserra R, Esposito M. The influence of smoking on the survival of dental implants: a 5-year pragmatic multicenter retrospective cohort study of 1727 patients. Eur J Oral Implantol. 2011:4:265-71.

52. Manzano G, Montero J, Martin-Vallejo J, Del Fabbro M, Bravo M, Testori T. Risk factors in early implant failure: a meta-analysis. Implant Dent. 2016;25: 272-80.

53. Papaioannou W, Quirynen M, Van Steenberghe D. The influence of periodontitis on the subgingival flora around implants in partially edentulous patients. Clin Oral Implants Res. 1996;7:405-9.

54. Danser M, van Winkelhoff A, de Graaff J, van der Velden U. Putative periodontal pathogens colonizing oral mucous membranes in denturewearing subjects with a past history of periodontitis. J Clin Periodontol. 1995;22:854-9

55. Kasai K, Takayama Y, Yokoyama A. Distribution of occlusal forces during occlusal adjustment of dental implant prostheses: a nonlinear finite element analysis considering the capacity for displacement of opposing teeth and implants. Int J Oral Maxillofac Implants. 2012;2:329-35.

56. Vandeweghe S, De Bruyn $\mathrm{H}$. The effect of smoking on early bone remodeling on surface modified southern implants. Clin Implant Dent Relat Res. 2011;13:206-14.

57. Keenan JR, Veitz-Keenan A. Antibiotic prophylaxis for dental implant placement. Evid Based Dent. 2015;16:52-3.

58. Lemos CA, de Souza Batista VE, Almeida DA, Saniago Júnior JF, Verri FR Pellizzer EP. Evaluation of cement-retained versus screw-retained implantsupported restorations for marginal bone loss: a systematic review and meta-analyses. J Prosthet Dent. 2016;115:419-27.

59. Donati M, Ekestubbe A, Lindhe J, Wennström JL. Marginal bone loss at implants with different surface characteristics - a 20-year follow-up of a randomized controlled clinical trial. Clin Oral Implants Res. 2018;29(5):480-7.

60. Jungner $\mathrm{M}$, Legrell $\mathrm{PE}$, Lundgren $\mathrm{S}$. Follow-up study of implants with turned or oxidized surfaces placed after sinus augmentation. Int J Oral Maxillofac Implants. 2014;29:1380-7.

61. Esposito M, Ardebili Y, Worthington HV. Intervention for replacing missing teeth: different types of dental implants. Cochrane Database Syst Rev. 2014; 22:CD003815

62. Doornewaard R, Christiaens V, De Bruyn H, Jacobsson M, Cosyn J, Vervaeke $\mathrm{S}$, Jacquet W. Long-term effect of surface roughness and patients' factors on crestal bone loss at dental implants. A systematic review and metaanalysis. Clin Implant Dent Relat Res. 2016;10:372-99.

\section{Submit your manuscript to a SpringerOpen ${ }^{\circ}$ journal and benefit from:}

- Convenient online submission

- Rigorous peer review

- Open access: articles freely available online

- High visibility within the field

- Retaining the copyright to your article

Submit your next manuscript at $\boldsymbol{\nabla}$ springeropen.com 